\title{
OPTIMIZATION OF WHEG ROBOT RUNNING WITH SIMULATION OF NEURO-FUZZY CONTROL
}

\author{
Bozic, M.*; Ducic, N. ${ }^{* \#}$; Djordjevic, G. ${ }^{* *} \&$ Slavkovic, R. ${ }^{*}$ \\ *University of Kragujevac, Faculty of Technical Sciences Cacak, Cacak, Serbia \\ ** University of Nis, Faculty of Electronic Engineering, Nis, Serbia \\ E-Mail: milos.bozic@ftn.kg.ac.rs, nedeljko.ducic@ftn.kg.ac.rs ( ${ }^{\#}$ Corresponding author), \\ goran.s.djordjevic@elfak.ni.ac.rs, radomir.slavkovic@ftn.kg.ac.rs
}

\begin{abstract}
This paper presents laboratory simulator for wheel - legged (Wheg) robot running and application for collecting measurement data. Data is used as a basis for modelling and optimization of energy consumption of running Wheg. The laboratory setup includes instrumented measurement treadmill (IMT) and Wheg drive. The laboratory experimental setup also includes the sensors, drives and software application. Intelligent modelling and optimization of energy usage during Wheg's running is based on a combination of neural networks and genetic algorithms. Neural network has established a correlation between the parameters of running. Using genetic algorithm optimal parameters for running are found. Simulation of neuro-fuzzy control system for minimization of energy usage during running was developed as a function of the angle and Wheg running speed.

(Received in February 2016, accepted in October 2016. This paper was with the authors 2 months for 2 revisions.)
\end{abstract}

Key Words: Instrumented Treadmill, Wheg, Neural Network, Genetic Algorithm, Neuro-Fuzzy Control

\section{INTRODUCTION}

The legs of insects, animals and humans allow them to move on flat and uneven terrain. Also, these creatures can walk on different types of substrates such as land grass, rocks, concrete, etc. Gait pattern in these creatures relatively easily adapts to the current state of the terrain. The current development state of the robots which mimics the gait of these creatures is not at that level and cannot be easily adapted to different types of terrains. Usually, the robots are created for specific types of terrain. No robot can still adapt to any type of terrain. Legged robots that have the possibility of moving over rough terrain are usually with complex structure. They have a large number of motors, complex control algorithms and they are inefficient. One of the most advanced legged robots today Atlas [1] is still not at that level that can autonomously navigate throw unknown terrain. There are many robot creations that are inspired by animals. One of well-known robots of this type is BigDog [2], as well as the fastest four-legged robot Cheetah [3]. Disadvantage of these robots is very poor energy efficiency due to the large number of actuators and rigid construction. There are a large number of robots in which the passive compliant elements in the various forms are used for robot legs like RHex [4]. This type of robot has a smaller number of actuators usually 6 as RHex or 4 like quad robots [5]. Large number of papers deals with the possibilities of increasing energy efficiency by usage of passive compliant legs [6]. The use of different configurations of compliant passive elements for legs affects the efficiency of robots (Fig.1 a) Also, change in flexibility of legs during robot's moving, affects the efficiency of robot and possibility to move over different terrain [7,8]. Authors in [9] introduced the concept of double Wheg $-\mathrm{dWheg}$ (Fig. 1b). Change of the angle $\alpha$ on dWheg affects the flexibility of Wheg spokes, which enables and optimize move over different terrain. The authors of this study did not analyse the energy consumption at different speeds and angle $\alpha$. The analysis can be carried out in three ways. The first method directly measures parameters on the robot 
during running in real environment, which is the most complex case to analyse. Second method is test the robot on a circular test station as the authors did in [10]. The third method is robot running on the motorized instrumented treadmill [11]. In this paper, we started from the first method while the future work plan is to analyse dWheg running in real environment by using the second and third method.
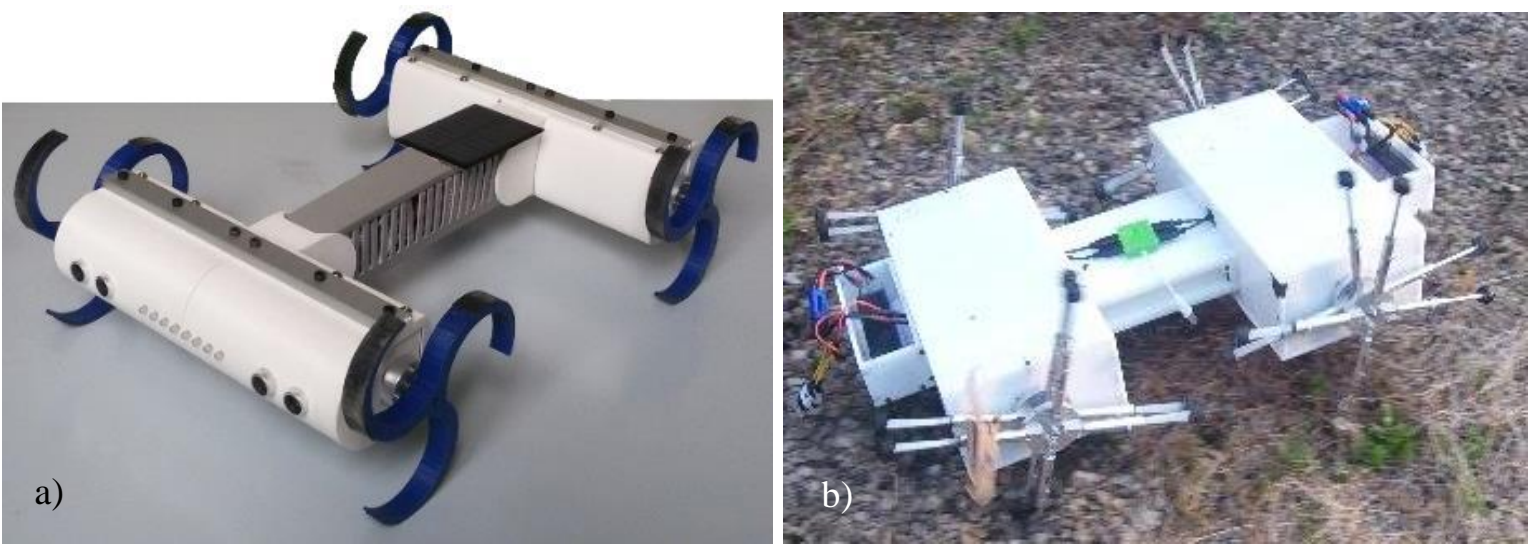

Figure 1: Robot with wheel - leg configuration: a) Wheg [12] and b) double Wheg - dWheg [9].

According to the authors' knowledge, up today, analysis of energy consumption of dWheg drives was not analysed. In this work characterization of energy consumption for different speeds $V_{w}[\mathrm{~m} / \mathrm{s}]$ and the angle $\alpha[\mathrm{deg}]$ for one type of terrain was carried out. Conducted modelling, optimization and control are based on techniques of artificial intelligence and their hybrid combinations, which also constitutes an improvement compared to the available research.

\section{LABORATORY SETUP FOR WHEG RUNNING SYMULATION}

Initial tests on dWheg are realized in laboratory environment with isolated change of parameters. The simulation of dWheg running is realized on a laboratory setup. Instrumented treadmill (ITM) is designed especially for characterization of C shape springs/spokes, to see effects of dWheg configuration on energy optimization. The ITM setup embodies several main elements: structural frame, treadmill, force measurement plate, drives with transmissions, controller and software. These and several other parts are given in the Fig. 2.

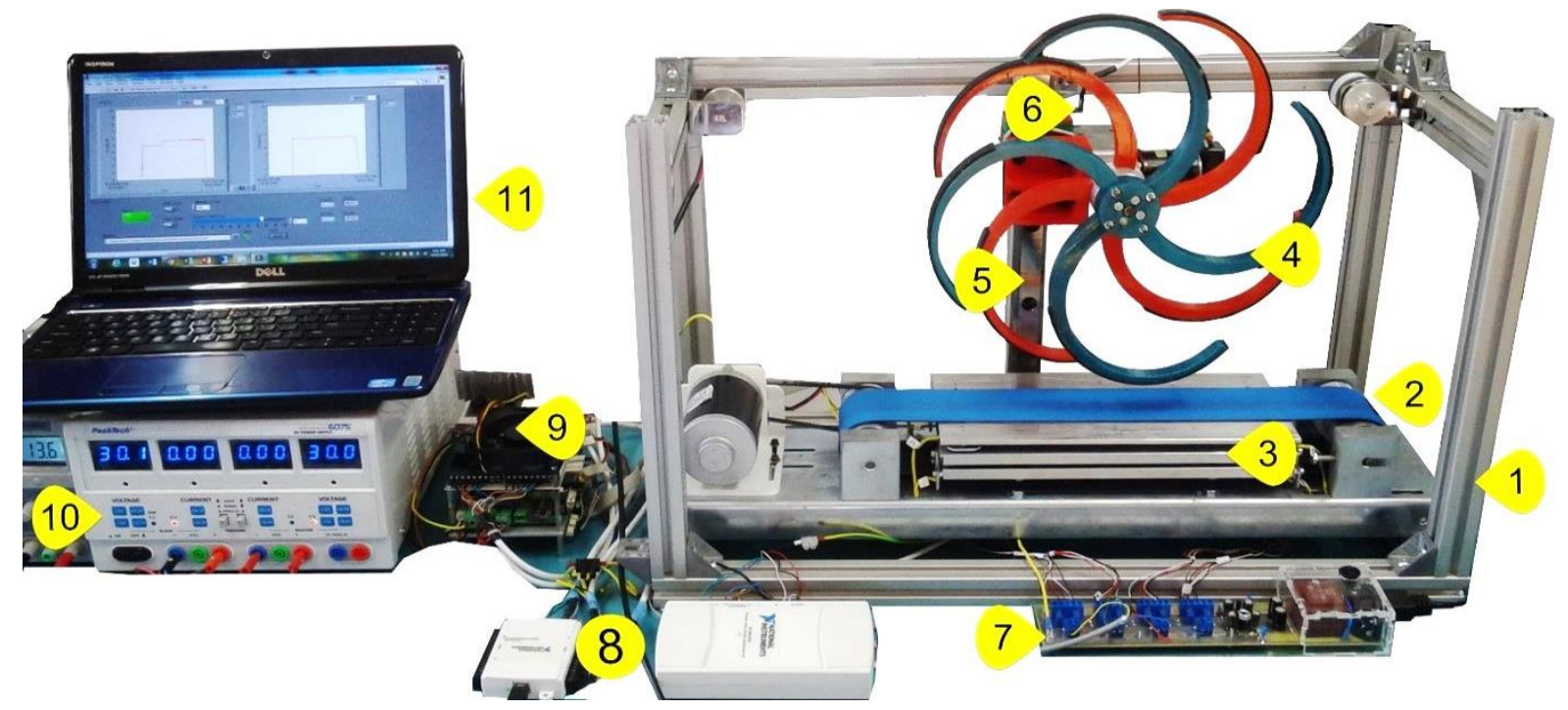

Figure 2: Instrumented treadmill station with DAQ system. 
The main parts of the ITM setup are: 1. Aluminum frame profiles for fast assembly and reconfiguration of experiment setup; 2 . Treadmill belt driven by power DC motor drive with incremental encoder and with pulley ratio $i=1.45 ; 3$. In treadmill force plate for measuring vertical and horizontal force components; 4. 3D printed Wheg PLA spokes with assembly for passive angle configuration coupled with Maxon motor with incremental encoder with gearbox $i=10 ; 5$. Linear guide rail with bearing cart for freely vertical movement; 6.3 axis accelerometer; 7. Four channel amplifier; 8. NI USB DAQ cards; 9. Two channel driver for DC motors; 10. Power supply; 11. Computer with LabVIEW application for control and measurements.

\section{1 dWheg design and realization}

With purpose to cut the time for testing various shapes of Wheg spokes, as well as reducing the cost of designing the prototype, rapid prototyping technology was used. During first tests, carbon fibre composite materials were used. Due to the manual and complicated process of making carbon spokes there was the big differences in flexibility of created spokes. For that reason, this making process is replaced by $3 \mathrm{D}$ printing. Various shapes of $3 \mathrm{D}$ printed Wheg spokes are designed and tested in order to find an adequate form with sufficient strength to meet the needs of this type of robot. The material used during the tests is polylactic acid (PLA). Although this material does not have good mechanical properties, this paper has shown that it can be successfully used for the purposes of prototype testing. In future work in the real environment testing more resistant materials will be used, such as Acrylonitrile butadiene styrene (ABS) and proto pasta.
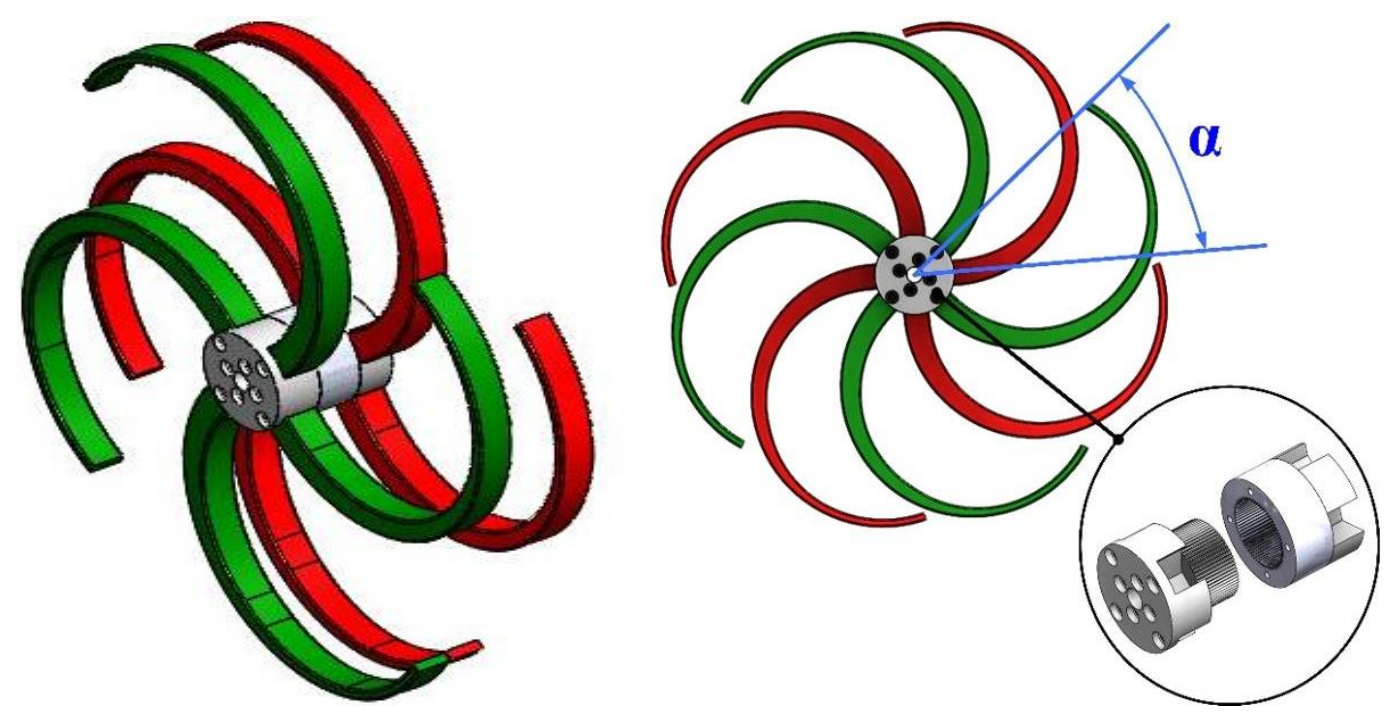

Figure 3: 3D Model of dWheg and assembly for angle configuration.

To enable the passive adjusting of the dWheg angle, aluminium male and female parts were made. This part allows adjusting the angle with a resolution of 5 degrees.

\subsection{Control of instrumented treadmill}

Complete block diagram of system is given in Fig. 4 a. Fig. 4 b shows the algorithm for control of laboratory setup. First step is to manually configure the angle $\alpha$, set initial speed and enter running distance. After this initial steps test procedure and speed synchronization can start. During the simulation of dWheg running it is necessary to ensure the synchronization of treadmill belt and dWheg peripheral speed. DWheg gets the reference speed from application but measured speed of dWheg represents a reference speed for a 
treadmill belt. Synchronization of speeds in this way is known as electronic gearing, because even without mechanical connection these two drives have the same speed based on encoder readout and PID regulation. $\Delta V$ is speed increment for new running cycle. In Fig. 5 part of LabVIEW application which doing synchronization is shown.

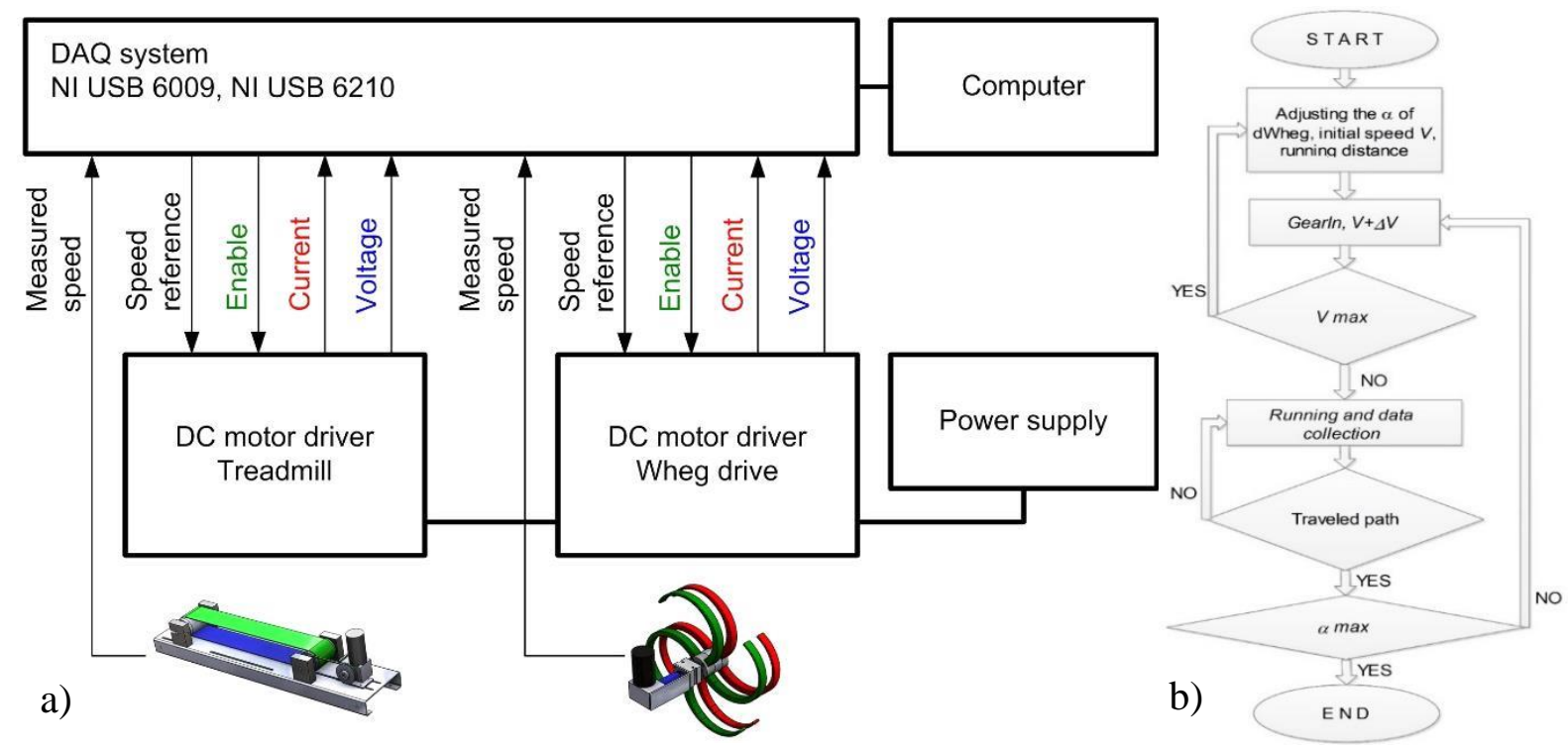

Figure 4: a) Block diagram of electrical connections and b) testing algorithm.

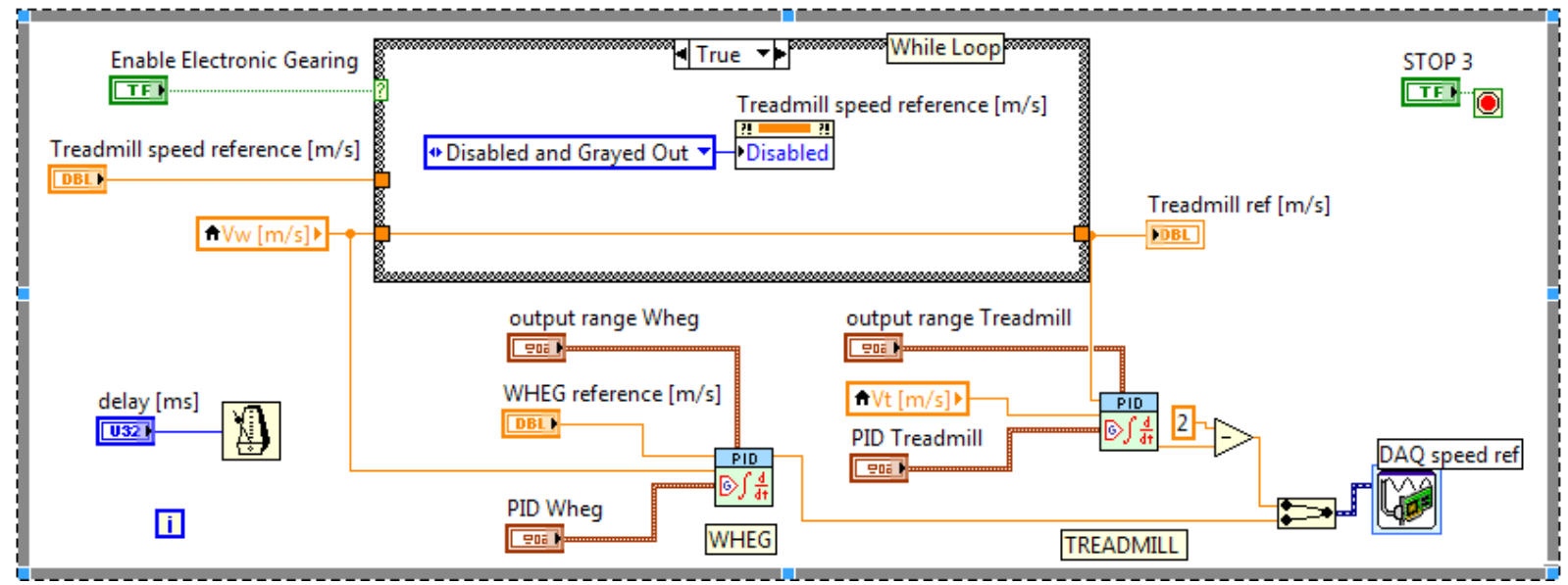

Figure 5: Block diagram of electronic gearing.

On the block diagram, there are two PID regulators. Wheg PID is regulating the speed of dWheg. Second PID is regulating the speed of treadmill. If the synchronization is turned off, speed references can be set independently. dWheg runs at one speed until it exceeds a set distance, after that increment $\Delta V$ is added and new cycle can start with new speed.

\subsection{LabVIEW application for measurement, data acquisition and control}

As a support to laboratory setup, LabVIEW application was created. This application has double function: control of laboratory setup and measurements of relevant parameters. In the next figure (Fig. 6) the user interface of application is given.

Application measures and saves values which are listed in Table I. Values shown in table are saved in appropriate files with names in following form: a45s4.1vm, a45 - that means angle of 45 degrees, and $s 4$ means speed of $4 \mathrm{~m} / \mathrm{s}$. These files are stored automatically and this name convention enables easier use of Matlab for data processing. 


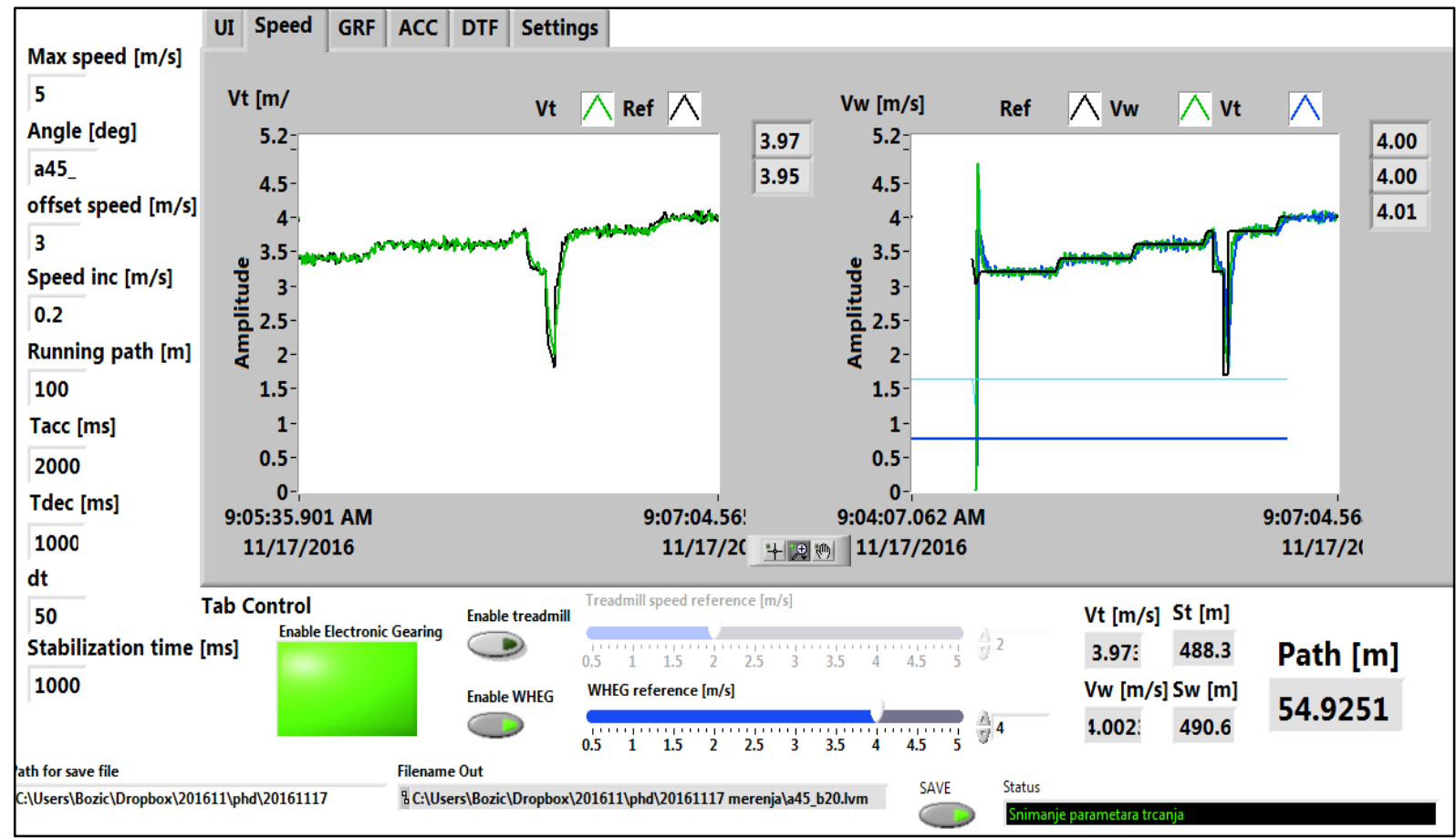

Figure 6: Application user interface.

Table I: The data that application stores.

\begin{tabular}{|c|c|c|}
\hline No. & Symbol & Description \\
\hline 1. & [ms] & The duration of one cycle of running \\
\hline 2. & {$[\mathrm{~A}]$} & The value of the treadmill motor current \\
\hline 3. & {$[\mathrm{~V}]$} & The value of voltage applied to treadmill motor \\
\hline 4. & $V_{T_{-} \mathrm{mes}}[\mathrm{m} / \mathrm{s}]$ & Treadmill measured speed \\
\hline 5. & $V_{T_{-} \text {ref }}[\mathrm{m} / \mathrm{s}]$ & Treadmill reference speed \\
\hline 6. & {$[\mathrm{~m} / \mathrm{s}]$} & Treadmill travelled path \\
\hline 7. & {$[\mathrm{~A}]$} & dWheg motor current \\
\hline 8. & $U_{W} \quad[\mathrm{~V}]$ & dWheg voltage applied on the motor \\
\hline 9. & $\begin{array}{ll}P_{W} & {[\mathrm{~W}]}\end{array}$ & Electrical power of dWheg motor, as $I_{W} \times U_{W}$ \\
\hline 10. & $V_{w_{-} \text {ref }}[\mathrm{m} / \mathrm{s}]$ & dWheg reference speed \\
\hline 11. & $V_{w_{-} \text {mer }}[\mathrm{m} / \mathrm{s}]$ & dWheg measured speed \\
\hline 12. & $S_{w} \quad[\mathrm{~m} / \mathrm{s}]$ & dWheg travelled path \\
\hline
\end{tabular}

Data collected using the application are after that automatically loaded and calculated by using scripts written in Matlab. Based on the measurements, which last up to a few hours the entire data set is then processed in a few seconds and displayed in the form of a suitable matrix for further processing or in form of surface which represents power or energy. Data prepared in this way are ready for processing by using neuro and fuzzy tools. 

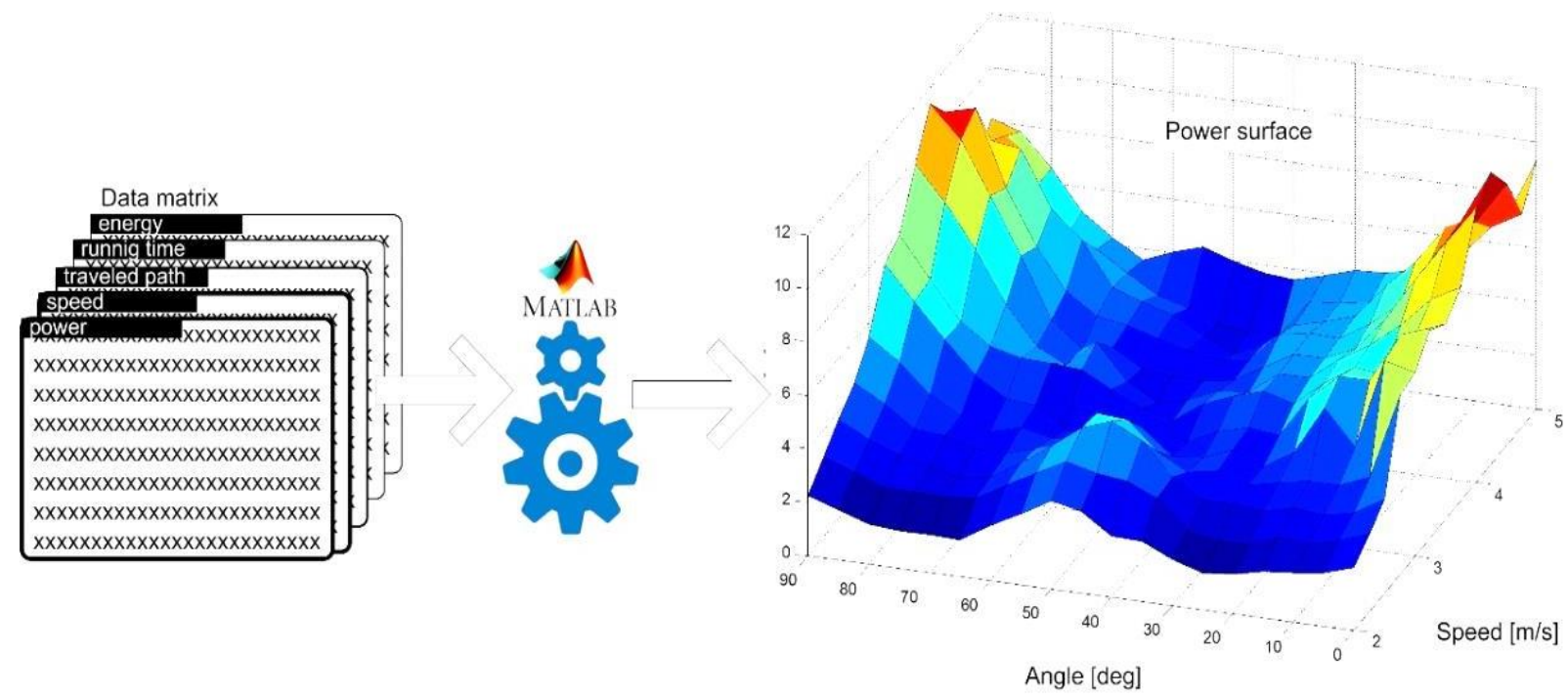

Figure 7: Steps during data processing.

\section{NEURO-GENETIC MODELLING AND OPTIMIZATION}

In this part of paper is presented methodology of establishing correlations between dWheg movement parameters in described experimental setup. For this purpose it is used artificial neural network. After making a correlation between parameters $(\alpha, V, P)$ of dWheg movement, by using a genetic algorithm, such movement parameters were found, for which the energy consumption is minimal.

\subsection{Prediction of energy consumption by using artificial neural networks}

Several architectures of neuro networks were developed to predict the energy consumption, based on experimental results, which are collected and was presented in section two. Movement speed of dWheg and angle $\alpha$ are inputs into the network. Output from the network is average power consumption for this configuration. In Fig. 8 is shown an overview of artificial neuron and network with these inputs and outputs, and one hidden layer which contains six neurons.

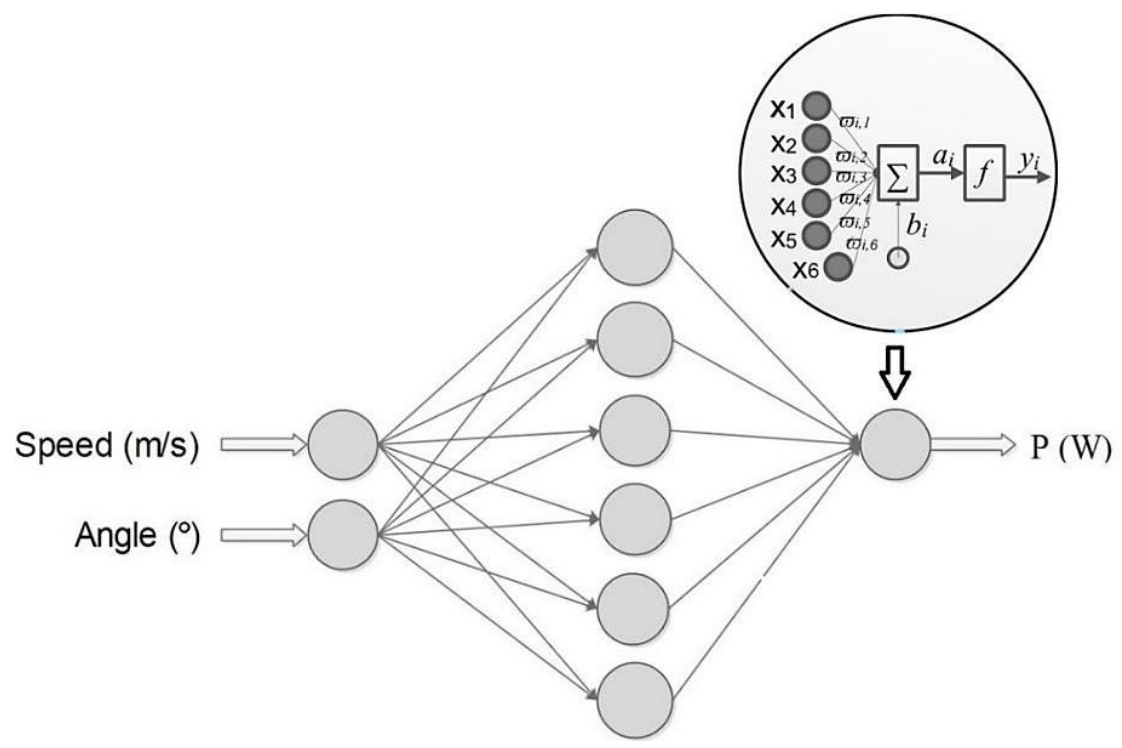

Figure 8: Artificial neuron and the structure of the feed forward artificial neural network. 
Each of inputs $x_{1}, x_{2}, \ldots, x_{6}$ is multiplied with the corresponding weight of the connection: $\varpi_{i, 1}, \varpi_{i, 2}, \ldots, \varpi_{i, 6}$. The neuron sums these values and adds a bias $b_{i}$ (lacking in some of the networks). The argument of the transfer function is stated in the following:

$$
a_{i}=x_{1} \varpi_{i, 1}+x_{2} \varpi_{i, 2}+\ldots+x_{6} \varpi_{i, 6}+b_{i}
$$

While neuron produces output:

$$
y_{i}=f\left(a_{i}\right)=f\left(\sum_{j=1}^{6} x_{j} \varpi_{i, 6}+b_{i}\right)
$$

This output is an input to the neurons of another layer, or an element of the output vector of the neural network. The principal aim is to reduce to a minimum the performance function, in this case mean squared error (MSE) function, which can be calculated as:

$$
M S E=\frac{1}{Q} \sum_{k=1}^{Q} e(k)^{2}=\frac{1}{Q} \sum_{k=1}^{Q}(t(k)-y(k))^{2}
$$

where: $Q$ - number of experiments, $e(k)$ - error, $t(k)$ - target values, $y(k)$ - predicted values. Algorithm of training is Levenberg-Marquardt algorithm which ensures the fast and stable convergence [13]. The neurons in input and hidden layers of neural networks have sigmoid transfer function, while the neurons of the output layer have linear transfer function. Overall number of experiments carried out is 247 . The dataset was randomly divided into training, validation and testing sets. The training sample (197 measurements) was presented to the network during training, and the network was adjusted according to its error. The validation sample (25 measurements) was used to measure network generalization, and to halt training when generalization stopped improving. The testing sample (25 measurements) had no effect on training and so provided an independent measure of network performance during and after training. As noted above, several feedforward - backpropagation architectures were created with different number of hidden layers and neurons in them. Of the several designed ANN models chosen is the one with the best characteristics. As a measure of validity the maximum error and mean error in the testing phase were used. The ANN 2-6-1 according to these criteria showed the best performance. Its maximum and mean errors are $8.73 \%$ and $4.18 \%$, respectively. Graphical overview of results of testing phase is shown in Fig. 9.

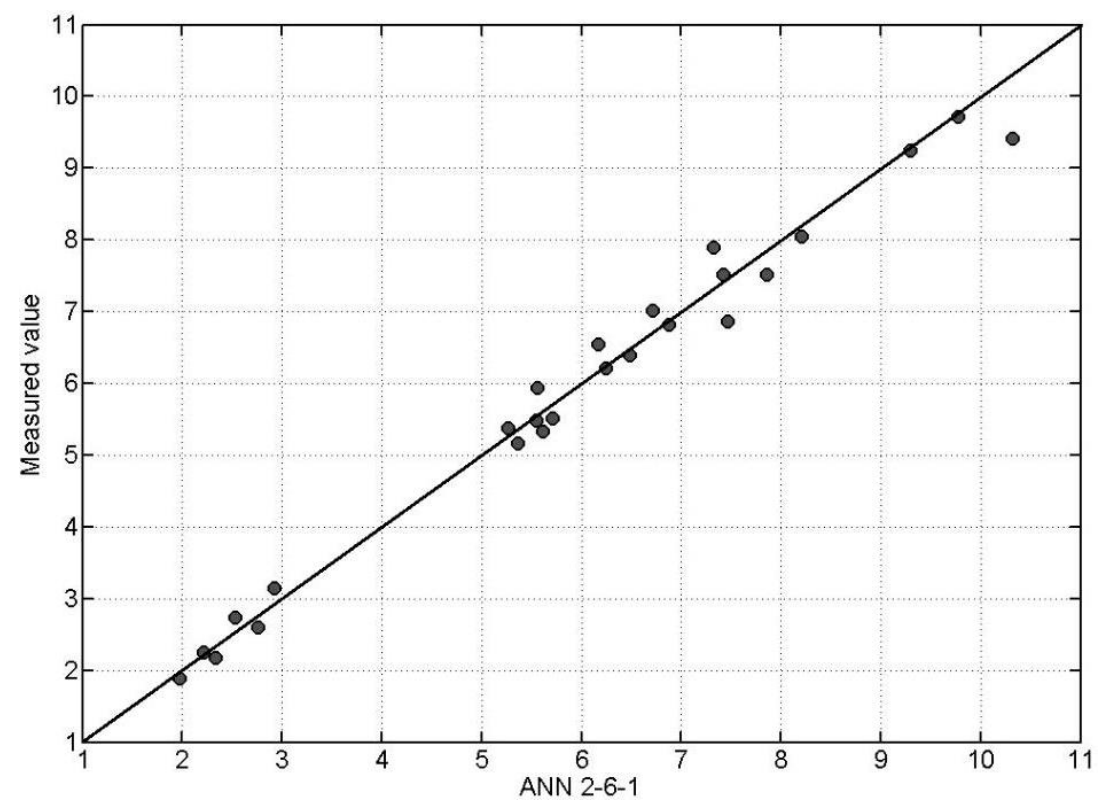

Figure 9: Comparison of the measured values with the results of ANN 2-6-1. 


\subsection{Optimization of energy using genetic algorithm}

The aim of this part of paper is the optimization of energy consumption, i.e. finding the optimal parameters (speed $V$ and angle $\alpha$ of dWheg) that require minimal power. For this purpose was used a genetic algorithm. Genetic algorithm (GA) is a heuristic method of global optimization, whose basics were proposed by John Holland. Its basics and working principle are described and analysed in the references [14-18]. In this particular case, the fitness function is a neural network model ANN 2-6-1, from the section 3.1. Optimization process by using the GA mechanism is shown in Fig. 10.

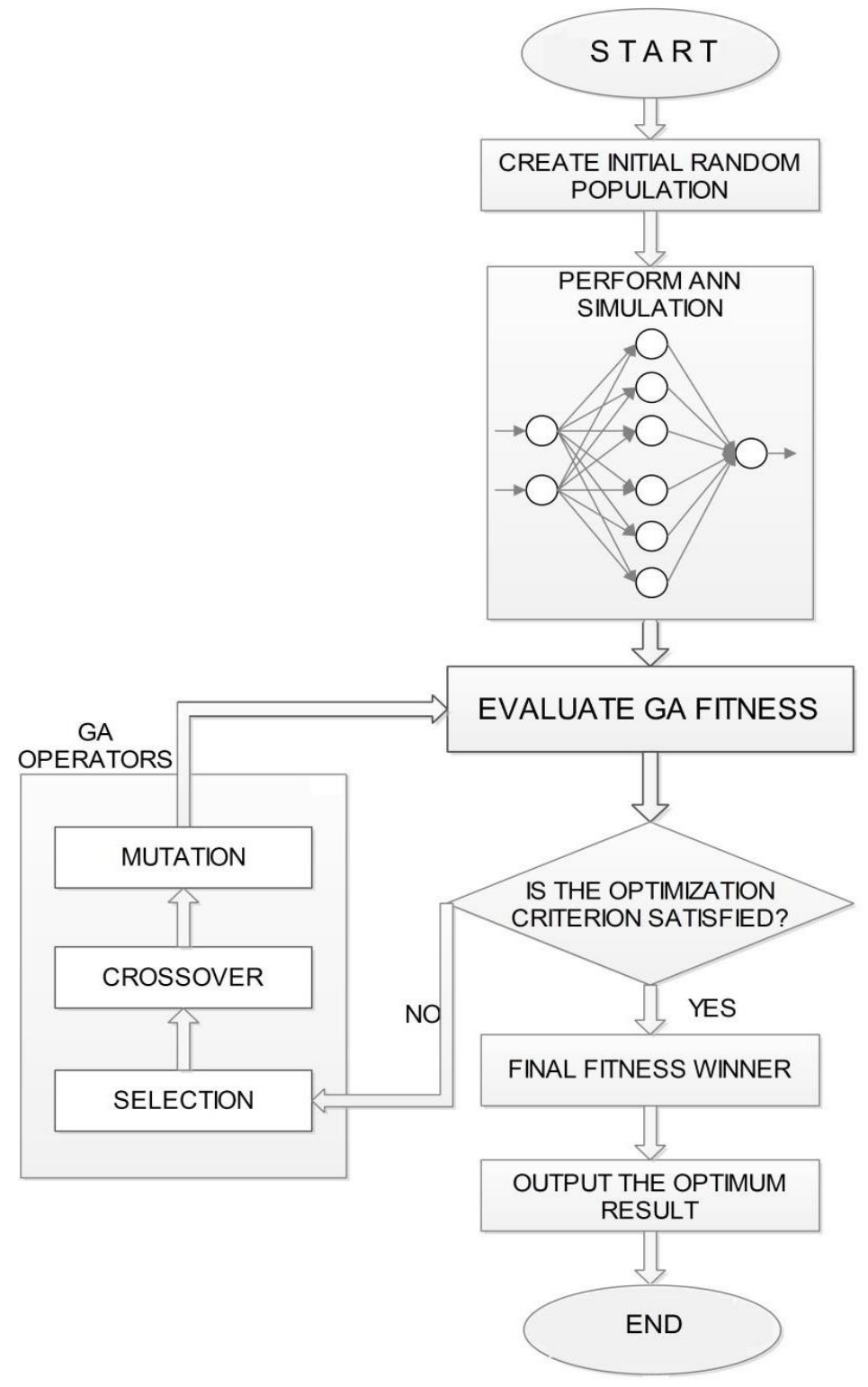

Figure 10: GA/ANN-based optimization algorithm.

The initial population has 40 individuals, and the maximum number of generations is set to 50. The selection process uses the stochastic universal sampling. The population is seen as mapped on the roulette-wheel, larger parts of the wheel belonging to strings with lower fitness. $N$ pointers are evenly placed on the roulette, $N$ being the number of individuals in a population. By turning the roulette is generated one population. As operator of crossing used uniform crossover operator. The coefficient of the 'crossover fraction' is 0.8. Crossover fraction (value between 0 and 1) defines a portion of the new population derived from a 
crossing (non-elite individuals). Not more than two elite individuals are to be transferred to the next generation. Genetic algorithm stops its work when it reaches the maximum number of defined generation - 50. The value of the minimized objective function is $1.31 \mathrm{~W}$, and parameters upon which the function has this value are: $V=2 \mathrm{~m} / \mathrm{s}$ and $\alpha=75^{\circ}$.
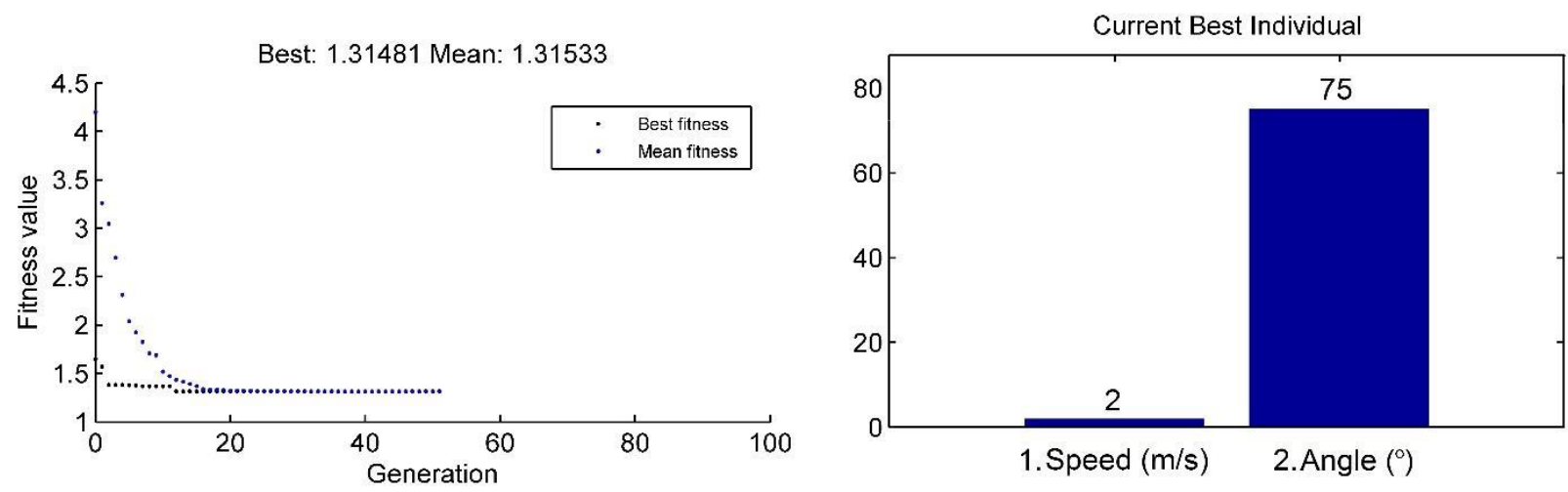

Figure 11: Process of optimization and results of optimization.

In this way, by using ANN-GA combination the optimal parameters for dWheg movement were obtained. The time, needed for $\mathrm{dWheg}$ to pass defined path is not taken as important parameter. The main goal was minimization of energy consumption.

\section{NEURO-FUZZY CONTROL OF MOVEMENT OF THE WHEG}

Simulation of control of dWheg movement aims to present the possibility of applying intelligent systems in control of this kind of robotic systems. In this section is presented the development of neuro-fuzzy controller for speed control as a function of the power and angle. Neuro-fuzzy systems are very popular systems that integrate neural networks and fuzzy logic. In this way, good characteristics of neural networks, such as learning ability and transparency were used as characteristic of fuzzy systems. A comprehensive review of the situation in the field of neuro-fuzzy systems is given in [18]. Jang (1993) suggests ANFIS (Adaptive Network based Fuzzy Inference System), which is the most commonly used neuro-fuzzy system [19]. Fig. 12 presents the architecture of ANFIS from five layers, where each layer has a clearly defined role. The principle of functioning neuro-fuzzy systems has been used based on literature, set forth in [20, 21].

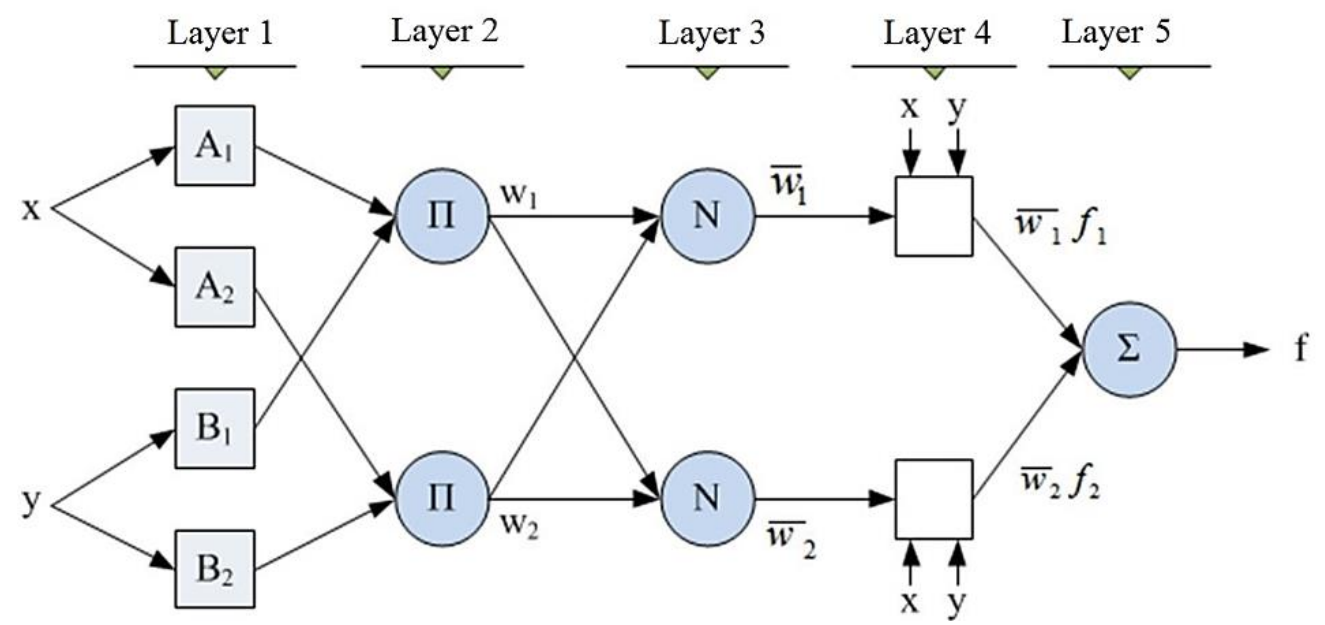

Figure 12: ANFIS architecture [21]. 
The aim of development of neuro-fuzzy controller is to control the speed of dWheg movement $V(\mathrm{~m} / \mathrm{s})$ in function of power $P(\mathrm{~W})$ and angle $\alpha\left({ }^{\circ}\right)$. Thus, neuro-fuzzy controller consists of two input parameters and one output parameter. Set of experimental data for controller development was used. In training phase backpropagation algorithm was used. Input values have five triangular membership functions, output function has linear character. Squared error after 1200 epochs is 0.61 in the training phase, while in the testing phase, in which participated a set of 25 data, the mean square error is 0.92 . Fig. 13 presents the neurofuzzy control surfaces, on which is shown a speed as a function of angle and configuration of dWheg.

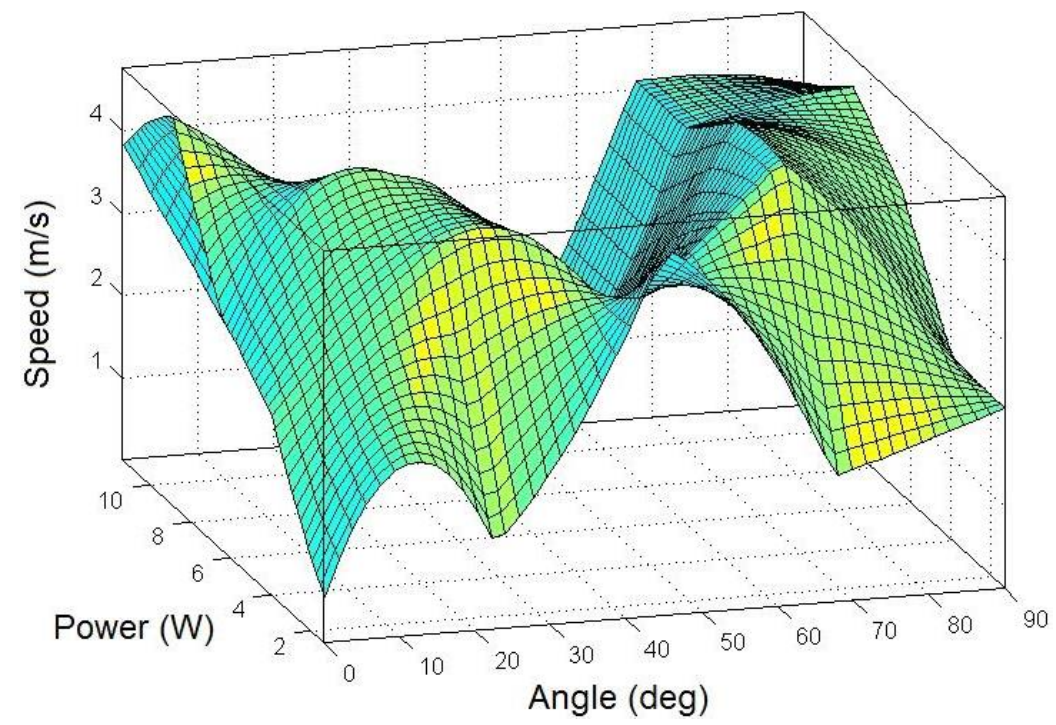

Figure 13: Neuro-fuzzy control surface.

After defuzzification process, the implementation of neuro-fuzzy controller in the LabVIEW environment was created. Control of speed based on neuro-fuzzy controller is realized according to the block shown in Fig. 14.

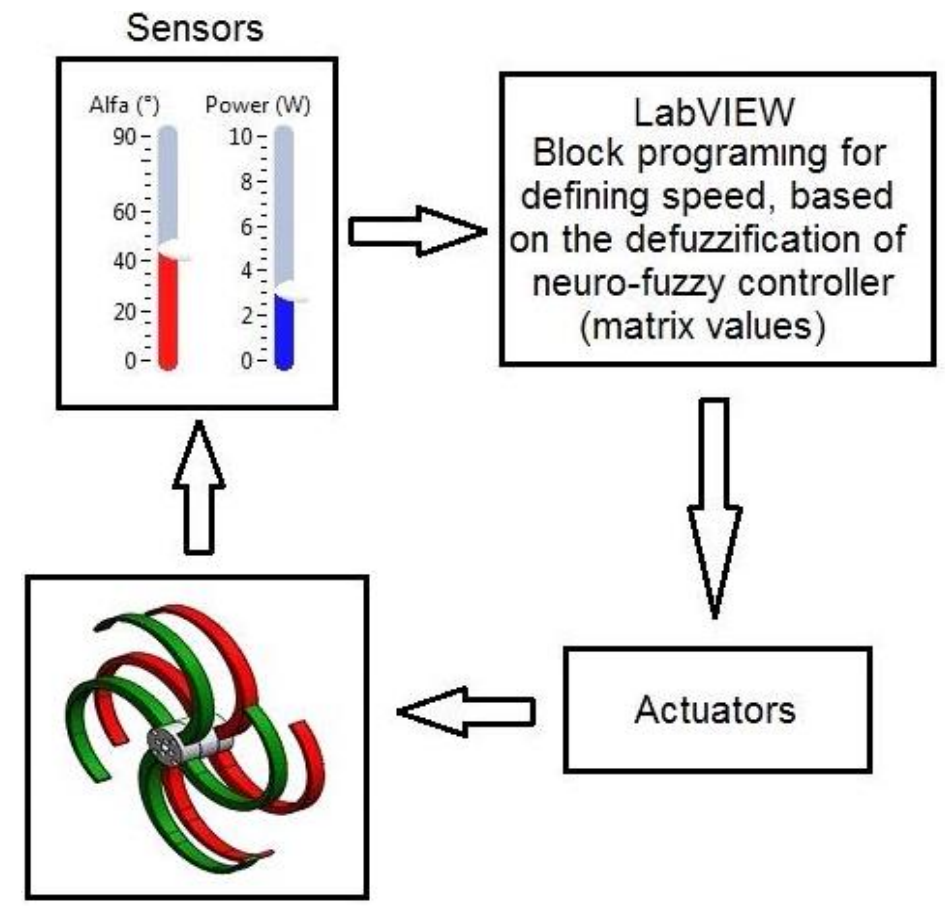

Figure 14: Neuro-fuzzy control block diagram. 


\section{CONCLUSION}

The paper was presented simulation of running dWheg on the instrumented treadmill. Complete laboratory setup was described. dWheg prototype design was presented. LabVIEW application for control and data collection was developed and described. Collected data is processed with Matlab scripts, which speed up process. The paper also described the possibility of applying artificial intelligence techniques in several directions. All directions had the same goal - to improve the movement of Wheg robot, and set goal has been fulfilled. The power consumption of movement of dWheg was modelled by artificial neural network. Combination of ANN-GA gave the optimal movement parameters for which the energy consumption is minimal. By hybrid combination of neural networks and fuzzy logic was presented the possibility to control the movement of the dWheg. Future work will deal with running of dWheg on different terrain, but the same algorithm will be used. Hypothesis, set in the beginning of the research about the possibility of applying artificial intelligence techniques in this field of robotics, is confirmed.

\section{REFERENCES}

[1] De Waard, M.; Inja, M.; Visser, A. (2013). Analysis of flat terrain for the atlas robot, $3^{\text {rd }}$ Joint Conference of AI \& Robotics and $5^{\text {th }}$ RoboCup Iran Open International Symposium (RIOS), 6 pages, doi:10.1109/RIOS.2013.6595324

[2] Wooden, D.; Malchano, M.; Blankespoor, K.; Howardy, A.; Rizzi, A. A.; Raibert, M. (2010) Autonomous navigation for BigDog, 2010 IEEE International Conference on Robotics and Automation (ICRA), 4736-4741, doi:10.1109/ROBOT.2010.5509226

[3] Wang, X.; Li, M.; Guo, W.; Wang, P.; Sun, L. (2012). Design and development of a cheetah robot under the neural mechanism controlling the leg's muscles, 2012 IEEE/RSJ International Conference on Intelligent Robots and Systems, 2749-2755, doi:10.1109/IROS.2012.6385462

[4] Saranli, U.; Buehler, M.; Koditschek, D. E. (2001). RHex: a simple and highly mobile hexapod robot, The International Journal of Robotics Research, Vol. 20, No. 7, 616-631, doi: $10.1177 / 02783640122067570$

[5] Morrey, J. M.; Lambrecht, B.; Horchler, A. D.; Ritzmann, R. E.; Quinn, R. D. (2003). Highly mobile and robust small quadruped robots, Proceedings of the 2003 IEEE/RSJ International Conference on Intelligent Robots and Systems, Vol. 1, 82-87, doi:10.1109/IROS.2003.1250609

[6] Jun, J.-Y. (2011). Characterization and optimization of running with curved legs, $\mathrm{PhD}$ Dissertation, The Florida State University, College of Engineering, Tallahassee

[7] Renjewski, D.; Sprowitz, A.; Peekema, A.; Jones, M.; Hurst, J. (2015). Exciting engineered passive dynamics in a bipedal robot, IEEE Transactions on Robotics, Vol. 31, No. 5, 1244-1251, doi:10.1109/TRO.2015.2473456

[8] Galloway, K. C.; Clark, J. E.; Koditschek, D. E. (2009). Design of a tunable stiffness composite leg for dynamic locomotion, Proceedings of IDETC/CIE 2009 - the ASME International Design Engineering Technical Conferences \& Computers and Information in Engineering Conference, paper ASME2009-86847, 8 pages

[9] Fremerey, M.; Djordjevic, G. S.; Witte, H. (2012). WARMOR: Whegs Adaptation and Reconfiguration of MOdular Robot with tunable compliance, Prescott, T. J.; Lepora, N. F.; Mura, A.; Verschure, P. F. M. J. (Eds.), Biomimetic and Biohybrid Systems (First International Conference, Living Machines 2012), Vol. 7375, 345-346, doi:10.1007/978-3-642-31525-1_35

[10] Raibert, M. H.; Brown, H. B. Jr. (1984). Experiments in balance with a 2D one-legged hopping machine, Journal of Dynamic Systems, Measurement, and Control, Vol. 106, No. 1, 75-81, doi: $10.1115 / 1.3149668$

[11] Božić, M.; Vujičić, V.; Đorđević, G. (2016). Realization of sensory mobile platform "WEGY" and possibilities of use in education, Proceedings of the $6^{\text {th }}$ International Conference Technics and Informatics in Education (TIO 2016), 417-422 
[12] Božić, M.; Božić, M.; Petković, M.; Sibinović, V.; Todorović, D.; Đorđević, G. S. (2014). Instrumentation treadmill for study of Wheg's dynamics, Proceedings of the $12^{\text {th }}$ International Conference on Systems, Automatic Control and Measurements (SAUM 2014), 176-179

[13] Hagan, M. T.; Menhaj, M. B. (1994). Training feed-forward networks with the Marquardt algorithm, IEEE Transactions on Neural Networks, Vol. 5, No. 6, 989-993, doi: $10.1109 / 72.329697$

[14] Holland, J. H. (1975). Adaptation in natural and artificial systems, University of Michigan Press, Ann Arbor

[15] De Jong, K. A. (1985). Genetic algorithms: A 10 year perspective, Proceedings of the $1^{\text {st }}$ International Conference on Genetic Algorithms and Their Applications, 169-177

[16] De Jong, K. (1988). Learning with genetic algorithms: An overview, Machine Learning, Vol. 3, No. 2-3, 121-138, doi:10.1007/BF00113894

[17] Goldberg, D. E. (2006). Genetic Algorithms in Search, Optimization, and Machine Learning, Pearson Education India

[18] Jang, J.-S. R. (1993). ANFIS: adaptive-network-based fuzzy inference system, IEEE Transactions on Systems, Man, and Cybernetics, Vol. 23, No. 3, 665-685, doi:10.1109/21.256541

[19] Abraham, A. (2005). Adaptation of fuzzy inference system using neural learning, Nedjah, N.; de Macedo Mourelle, L. (Eds.), Fuzzy Systems Engineering, Vol. 181, Studies in Fuzziness and Soft Computing, Springer, Berlin, 53-83

[20] Shoorehdeli, M. A.; Teshnehlab, M.; Sedigh, A. K.; Khanesar, M. A. (2009). Identification using ANFIS with intelligent hybrid stable learning algorithm approaches and stability analysis of training methods, Applied Soft Computing, Vol. 9, No. 2, 833-850, doi:10.1016/ j.asoc.2008.11.001

[21] Dučić, N.; Milićević, I.; Ćojbašić, Ž.; Manasijević, S.; Radiša, R.; Slavković, R.; Božić, M. Intelligent system for automatic control of the process of filling the mold, The International Journal of Advanced Manufacturing Technology, First Online: Oct. 2016, 9 pages, doi:10.1007/s00170-016-9552-x 